\title{
Prevalence of dementia in a rural nursing home population in Southern Germany
}

\author{
P. Hutsteiner* \\ S. Galler* \\ M.C. Mendoza** \\ H.H. Klünemann** \\ * University of Regensburg \\ ** Department of Psychiatry and \\ Psychosomatic Medicine, University \\ of Regensburg \\ GERMANY
}

\begin{abstract}
Background and Objectives: We sought to obtain data about the prevalence of dementia in rural nursing homes in Germany.

Methods: We conducted our data between 2007 and 2009 in the diocese of Passau, Germany. By using a questionnaire we asked all nursing homes in the area to provide information about patients with dementia. We obtained detailed data from three nursing homes by personal visits, telephone calls and mail.

Results: Out of 72 nursing homes, 40 provided the requested data. The 40 facilities included in our study house a total of 3,928 residents, 1,892 of whom are diagnosed with dementia (48\%). Three nursing homes provided us with more detailed information.

Conclusions: We conclude that the prevalence of dementia in nursing homes in Germany is comparable to those rates reported in other countries. As there is a lack of information globally on rural populations affected by dementia, further international research in this area will give important insights into the risk factors, the variables influencing the course of the disease, and the special care needs of this population.
\end{abstract}

Received: 4 April 2012

Revised: 20 February 2013

Accepted: 15 April 2013 


\section{Background}

With the increasing number of people with dementia and the aging population worldwide, the nursing home has taken on a prominent role as a care setting for older persons. However, surprisingly little is known about the prevalence of dementia among nursing home residents. As a current estimate from 2002 shows, there are approximately one million people in Germany suffering from dementia ${ }^{1}$. According to the data of the Federal Institute for Population Research 709,311 Germans lived in nursing homes and care facilities in 2007. Previous work in other western countries on dementia prevalence in nursing homes suggests that $25 \%-74 \%$ of all nursing home residents have dementia ${ }^{2,3}$, but there are no comparable studies for German nursing homes, especially regarding the rural areas.

There exist a few studies focusing on the prevalence of dementia within residents in urban nursing homes ${ }^{4,5}$. Only nineteen studies focusing on dementia in rural settings are reported globally ${ }^{6}$. None of these studies reports on the rural population with dementia in Germany. Extrapolating from findings of other studies in Japan and Portugal, dementia may be more prevalent in rural as compared to urban settings ${ }^{7,8}$.

The present study grew out of a need to investigate dementia in the rural nursing home population in Germany, as this is an underreported and under-diagnosed area.

\section{Methods}

To gather information about demented elderly living in nursing homes, we searched electronic databases such as PubMed and
Medline for studies in English and German on the prevalence of dementia worldwide, particularly in rural areas, using medical subjects as key words, for example "dementia AND prevalence" combined with "residential care" and "rural area". Likewise we used the subjects "Alzheimer's disease", "rate", "incidence", "population" and "nursing home". We included all issues found from August 1986 until June 2010 that describe and comment on studies relevant to the prevalence of dementia. Other studies and further information were found within the reference lists of the included studies. We also contacted the German Alzheimer's Society and the German Federal Institute for Population Research.

Our study was conducted between 2007 and 2009 on the total population living in the diocese of Passau in southern Germany. From 1217 until 1803 this geographic region was officially defined as a diocese in accordance with church-state administration of the Roman Catholic Church and thereafter secularized, however preserving the borders of the diocese as a distinct geographic region. We use this area for genetic research because the diocese of Passau has a historic population data base dating from 1580 to 1900 with data for two million deceased inhabitants of this area and has a stable population. This makes it easier to connect seemingly sporadic cases of dementia by genealogical methods ${ }^{9-11}$.

Regions of OECD (Organisation for Economic Co-operation and Development) member countries have been classified into predominantly urban, intermediate and predominantly rural regions to take into account geographical differences among them. According to the OECD, a community is defined as rural if its population density is below 150 inhabitants per square kilometer. The second criterion classifies regions according to the percentage of population living in rural communities. Thus, a region is classified as pre- 
dominantly rural, if more than $50 \%$ of its population lives in rural communities. A region is defined as predominantly urban, if the share of population living in rural communities is below $15 \%$ and as an intermediate region, if the share of population living in rural communities is between $15 \%$ and $50 \%^{12}$.
We contacted all 72 nursing homes and care facilities in our research area, excluding the nursing homes in the urban areas of the cities of Passau and Altötting. All institutions we contacted shared the characteristics of both typical senior citizen care facilities in Germany: retirement homes and nursing

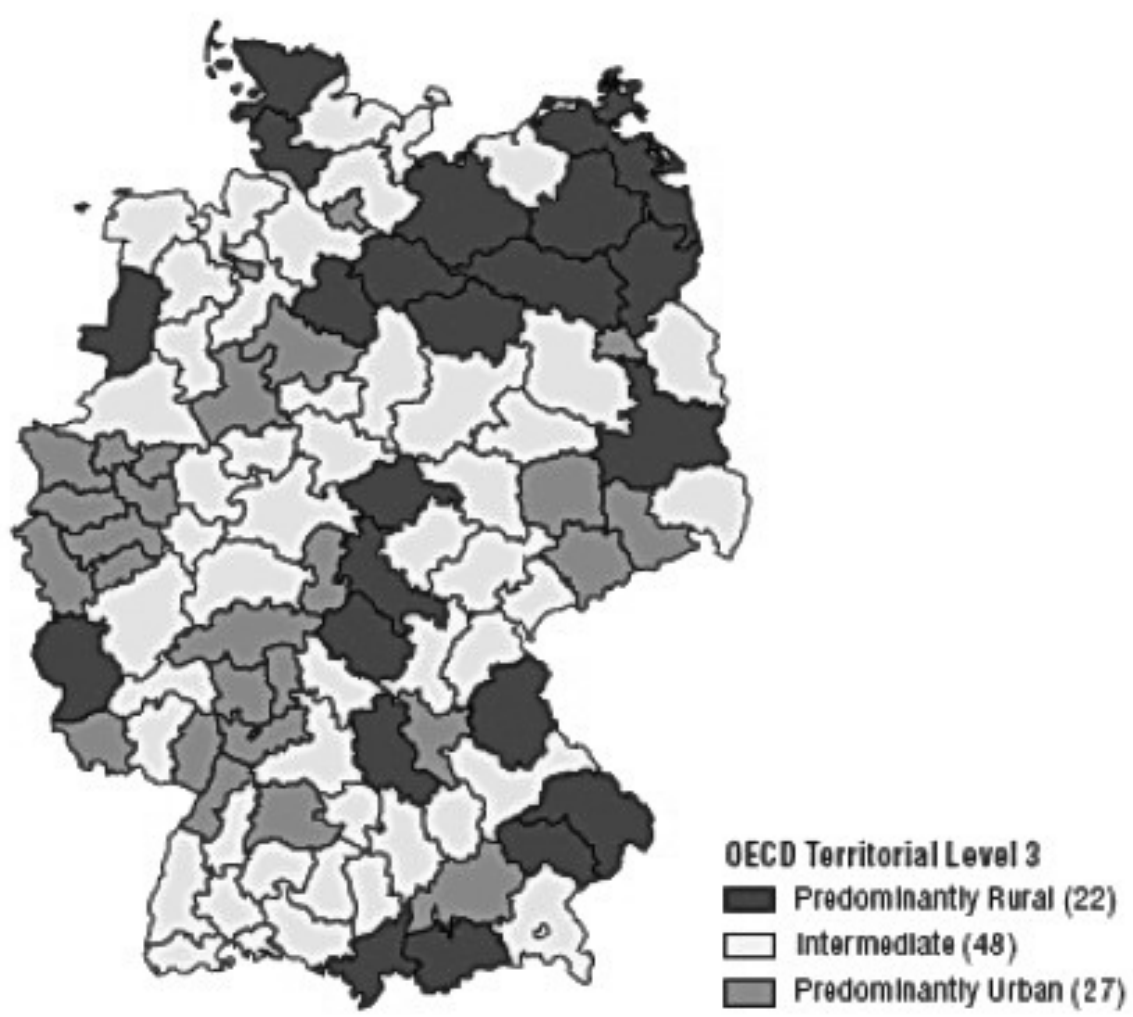

Figure 1. OECD Territorial Levels.

Source: OECD (2007a), OECD Regions at a Glance, OECD Publications, Paris, France, forthcoming.

homes. A retirement home or care home differs from a nursing home primarily in the level of medical care given, it mainly offers separate and autonomous homes for residents. Nursing homes offer 24 hours nursing care by nurses and nursing aides for people who require constant nursing care and have significant deficiencies with activities of daily living. In the remainder of the paper "nursing homes" refers to both types of care facilities. 


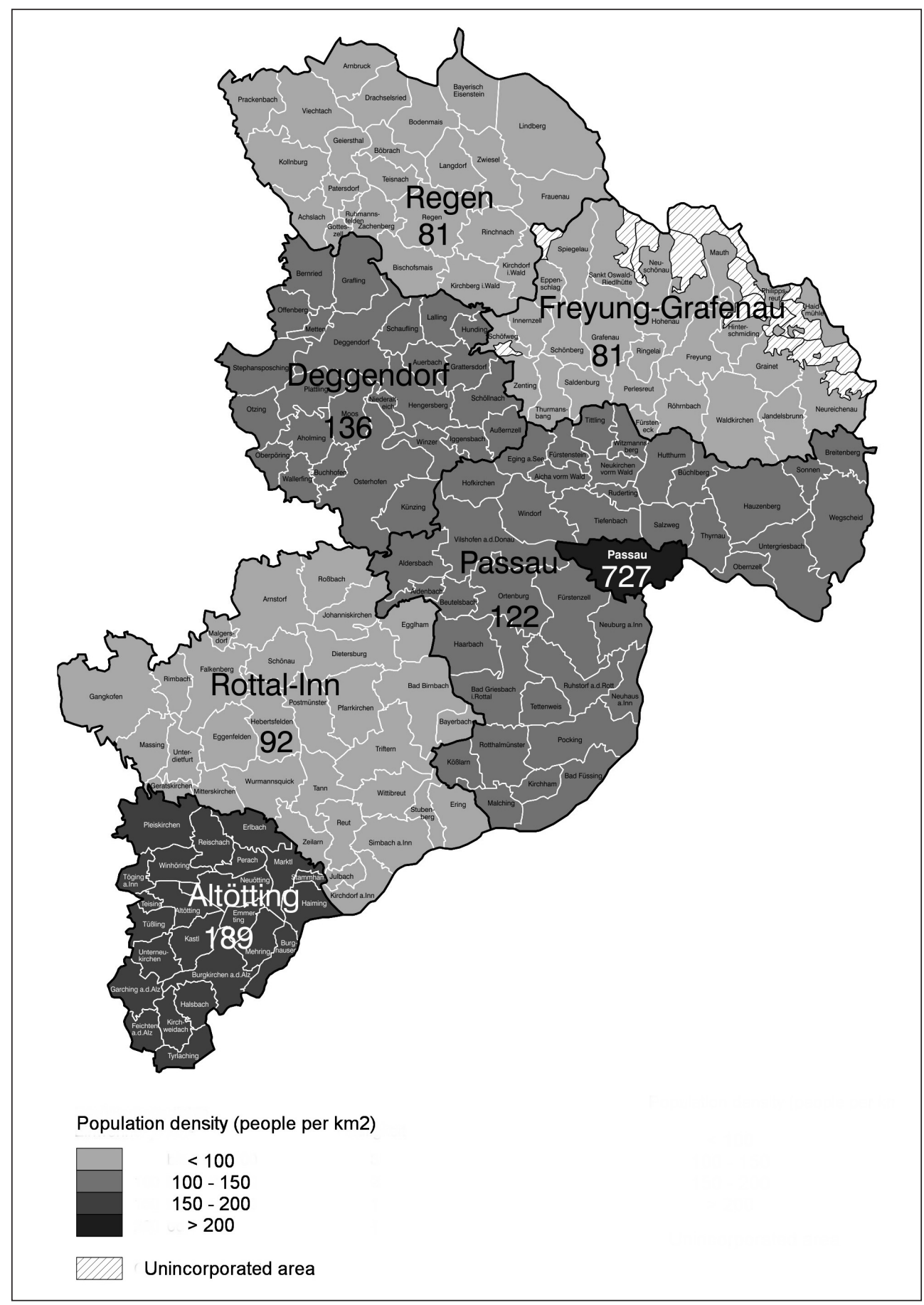

Figure 2. Population Density of the Diocese of Passau. 
We designed a questionnaire to elicit information about their residents with dementia. Nursing homes were contacted in person, by telephone, and through the mail and were asked to provide their total number of residents, the number of residents diagnosed with dementia, and, of those with dementia, their exact diagnosis, gender and age. We obtained detailed data including age, gender, birth place, ethnic group, marital status and the exact International Classification of Diseases (ICD -10) diagnosis from three nursing homes by medical records review, from interviews with residents, staff interviews and interviews with the relatives of the residents. The three nursing homes which provided us the possibility to collect further data were of above average number of residents, their resident had a similar average age, they had the same distribution between the sexes and had a similar catchment area. The diagnosis of dementia in the 222 residents was initially determined through clinical interview and examination conducted by a geriatric psychiatrist or a general practitioner and was based on the Diagnostic and Statistical Manual of Mental Disorders (DSM-IV) criteria and the ICD 10 criteria. In order to confirm the dementia diagnoses, we then conducted Folstein Mini-Mental Status Tests and, in those patients whose cognitive condition allowed further testing, we applied the Consortium to Establish a Registry for Alzheimer's disease (CERAD) neuropsychological test panel. Review of medical records and further interviews with nursing home staff and relatives of the patients were also used to confirm the diagnoses.

\section{Results}

Our study was conducted in the diocese of Passau (southern Germany) which has a total population of 566,882 inhabitants in an area of $5,442 \mathrm{~km}^{213}$.
We contacted a total of 72 nursing homes. Twenty-nine care facilities did not provide information. Three facilities were day care centres or institutions for the mentally challenged and were thus excluded from the study. The remaining 40 nursing homes had a total of 3,928 residents, with 1,892 residents diagnosed with dementia (48\%; $95 \%$ confidence interval (CI): 47.2-48.8). 2,278 residents of all nursing homes contacted were female $(58 \%), 1,650$ residents were male (42\%), 1,153 female residents (29\%) and 739 male residents (19\%) were diagnosed with dementia.

Additionally, three nursing homes provided detailed data. In these facilities of 222 residents, 123 individuals carry a diagnosis of dementia (55\%; 95\% CI: 51.6-58.4). Average age of residents with dementia was 81 years, with a range of 46 to 97 years. 63 percent of these residents were female and 37 percent male. The following distribution of diagnoses was collected: 2 of 123 were diagnosed with physical disability and dementia (2\%), 10 of 123 with organic psychotic disorder (ICD 10 F 06.2, F 07.9) (8\%), another $15 \%$ with Alzheimer's disease (onset of disease before 65 years, ICD 10 F 00.0), 12 of 123 with dementia caused by alcohol abuse (ICD $10 \mathrm{~F}$ 10.6) (10\%), 23 of 123 with senile dementia with an age of onset above 65 years (ICD 10 F 00.1) (19\%) and 56 of 123 had the undifferentiated diagnosis of dementia (ICD $10 \mathrm{~F}$ 03) $(46 \%)$.

\section{Discussion}

We compared our found rate of dementia to all other studies in our literature research on the prevalence of dementia in nursing homes worldwide (see table 1).

The dementia rate of $48 \%$ in our nursing homes replicates the results of a similar study 


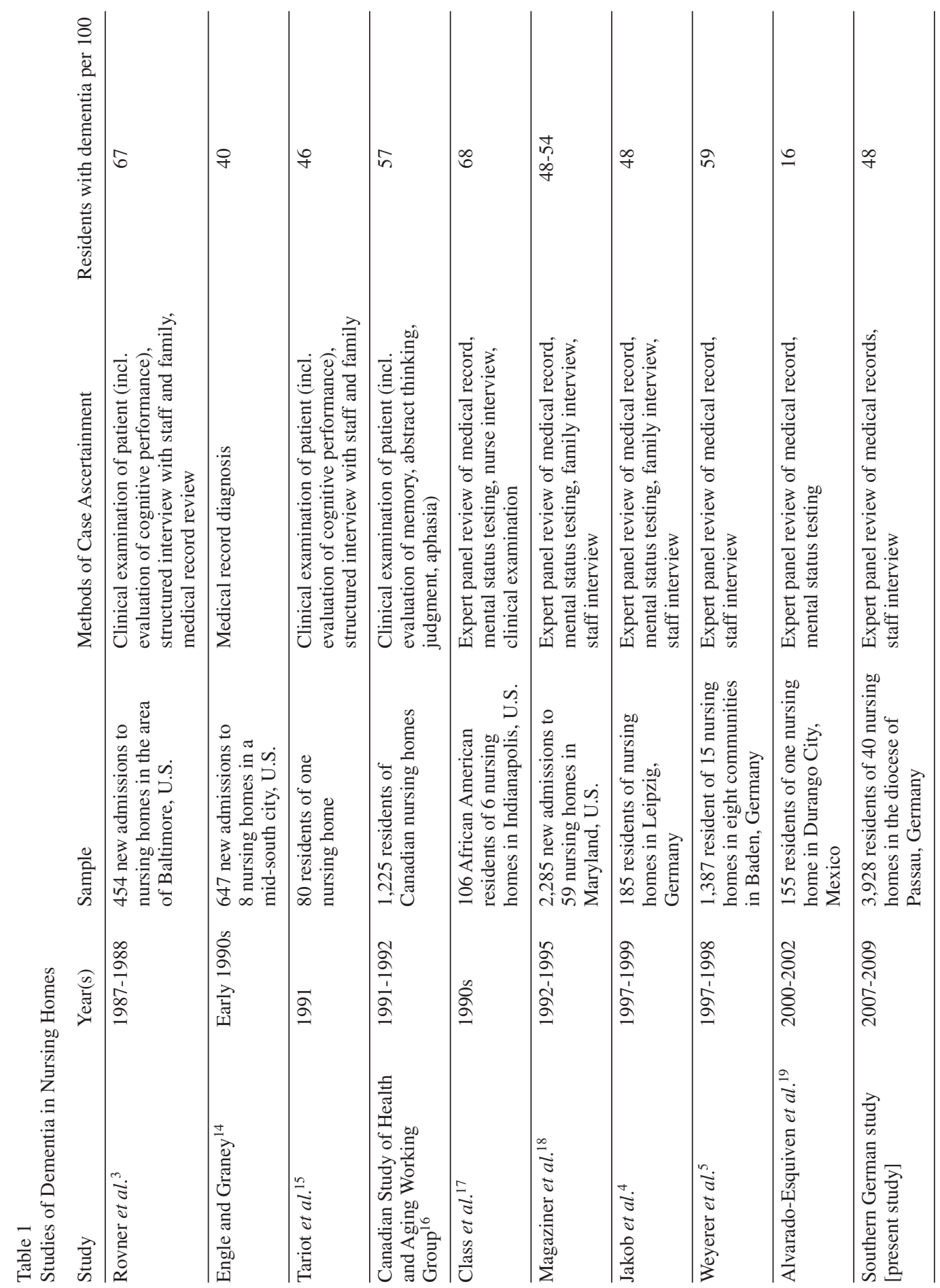


of 59 nursing homes in the state of Maryland, $\mathrm{USA}^{18}$ and the results found in another German study which surveyed the elderly population in the city of Leipzig ${ }^{4}$. Previous studies of dementia prevalence in nursing homes suggest rates of $25 \%-74 \%$ of all residents ${ }^{2,3}$. The variability seen in these studies can in large part be attributed to the data collection method used $^{18}$. The rate of only $16 \%$ found in the Durango study might be due to the low number of people screened, the low average age of 72.5 years, low percentage of contributing risk factors, and gender (much higher percentage of women in the study population) in comparison to other studies.

We speculate that our found rate of 48 percent is an underestimation as not every resident may necessarily undergo a detailed clinical, neurological and psychological examination for dementia. A study from the University of Bochum (2007) showed that $40 \%$ of their subjects were not diagnosed with dementia according to ICD-10 criteria $^{20}$.

In our research area, there are a total of 48 neurologists and psychiatrists and in contrast a total of 386 general practitioners ${ }^{21}$. This number of specialists might underlie the lower rate of dementia due to distinctive diagnostic procedures by specialists as opposed to general practitioners, as found in the study by Rovner et al. $1990^{3}$. Unfortunately none of the studies in our review reported on the number of specialists in their research area so no comparison can be made.

The rate of dementia we found in the three nursing homes is slightly higher $(55 \%)$ than the average rate we found with the survey-obtained method (48\%). This might be due to the monthly consultations by a neurologist in two of the three nursing homes.

We speculate that the nursing homes which didn't provide detailed data may lack specialised diagnostics for dementia, so that in these centers dementia may be underdiagnosed.

We state more reasons later on regarding homes that did not provide detailed info and those that did not respond.

Our data was collected from medical records and interviews and reviewed by an expert panel of clinical/research psychiatrists in our Memory Clinic. This method might be a potential limitation of the study as the residents were, in most cases, due to logistics not followed for any additional information and examinations to confirm the diagnoses. An additional challenge to studying nursing home populations worldwide is the logistical difficulty of having residents travel to a central site for diagnosis, which makes a multistage screening and clinical diagnosis process costly and hard to implement. Under-detection has significant implications for the affected residents: suboptimal treatment with medication and a lack of specialized care.

Epidemiologic studies from other western countries show that $55-75 \%$ of dementia is caused by Alzheimer's disease; $15-25 \%$ is caused by vascular dementia and 10-20\% suffer from combinations of vascular and degenerative forms of dementia ${ }^{22}$. The reported rate of $15 \%$ of patients with Alzheimer's disease in our study is low compared to the general rate of $\mathrm{AD}$. This may reflect the problem of diagnosis ${ }^{23}$. Specialized diagnostic tests such as brain amyloid imaging ${ }^{24,25}$ are costly and not widely available. Neuropsychiatric testing is time-consuming and therefore not often realized. Current studies show a lack of diagnostic and therapeutic precision in dementia among nursing home populations ${ }^{20}$. The percentages of $\mathrm{AD}(15 \%)$, senile dementia $(19 \%)$, and unspecified dementia (46\%) together total $80 \%$, which mirrors the epidemiologic data for $\mathrm{AD}$ in other studies. It is also impossible to determine an exact preva- 
lence rate for chronic diseases such as dementia which usually have an insidious progress from mild impairment to its manifest form ${ }^{26}$.

The average age of 81 years in our population reflects the approximate age of 80 years in a cross-sectional study with 1,387 nursing home residents in Baden, Germany ${ }^{6}$. This age is not representative of dementia prevalence in the general population: it can be assumed that at the beginning of the disease most individuals are supported by caregivers at home and that the need for admission to nursing homes arises in the much more advanced stages of the disease.

In our review of the literature, nineteen studies focusing on dementia or related disorders in rural settings have been reported worldwide. None of these studies reports on the rural population with dementia in Germany and none of these studies differentiated between rural, semi-urban and urban but rather between rural and urban. $47 \%$ of the German population live in non-urban areas where disease screening and diagnosis and delivery of medical care are comparatively more difficult than in urban settings. Globally, dementia may be more common in rural settings compared to non-urban settings ${ }^{6}$. An epidemiological study in Japan found a higher rate of dementia in a rural area compared to an urban area ${ }^{7}$. Another epidemiologic study of Portugal which investigated the prevalence of dementia and cognitive impairment in Northern Portugal rural and urban populations aged 55-79 years showed a higher prevalence of cognitive impairment and dementia in rural compared to urban populations ${ }^{8}$.

One reason for this might be the higher rate of illiteracy and lower levels of education as established risk factors for earlier onset of dementia ${ }^{8,27,28}$. As shown in the First Euro- pean Quality of Life Survey, the educational level in rural areas is lower: more people have completed a primary education (25\%) than university degree (13\%) compared to urban areas with $18 \%$ of people with primary education and $22 \%$ of people with an university degree ${ }^{29}$. Another risk factor which is often described in literature is unskilled occupations which are especially popular in rural areas 28,30 .

Yet another possible factor in the differing rates of dementia in rural versus urban population might be the higher life expectancy due to deprivation in rural areas compared to urban areas as show in England ${ }^{31}$ and the resulting higher age is an important risk factor for dementia. Shucksmith et al. define "deprivation" as a set of economic and social conditions which have the potential to cause problems for individuals or particular social groups within rural areas, or a lack of resources (material, cultural, social) which excludes people from the styles of life open to the majority in the countryside ${ }^{32}$. A request at the German Federal Institute of Population Research couldn't provide data on life expectancy subdivided in rural and urban areas in Germany.

Finding possible different risk factors for cognitive impairment in the differences between rural and urban areas can be important in allocation of resources in rural and urban areas $^{8}$. Furthermore, our determination of a 48 percent prevalence rate of dementia may be much lower than the actual rate, as in rural families it is more common to maintain demented elders in the community and deliver care and social support in the home ${ }^{6}$.

Another potential limitation of the present study is its setting in the single German federal state of Bavaria. We assume that terms and conditions for nursing home residents are the same in other German federal states 
but some caution is still required when generalizing our results.

An additional limiting factor in our study is the lack of data concerning the socio-economic status and the level of education in our study population. Furthermore, limited resources prevented a further comparative study between rural and urban populations, which might provide more significant results concerning the differences.

37 of the 40 responding nursing homes did not provide detailed data, such as the exact ages of the residents and specific diagnoses. This might be due to regulations of data protection and legal requirements concerning confidential medical communication, which may be complicated with demented residents, who often have legal representatives $^{33}$.

The 29 nursing homes that did not respond to the survey did not differ systematically from the others concerning size, location of the facility and the type of patients they house. The only difference could be found in the ownership of those nursing homes: 24 of the 29 facilities had private owners and 5 were owned by the church (17\%), whereas in the group of 40 homes that responded 19 were church-owned (48\%). One factor that may contribute to the variable response rate could be variable personnel resources available for collecting the data from the residents in those nursing homes.

The response rate of the nursing homes was $60 \%$. With regard to the $40 \%$ of non-responding sites, we estimate another 2,619 people living in those facilities and another 1,261 people with dementia among them. Thus, in this diocese of 566,882 inhabitants, we estimate a total number of 6,547 nursing home residents $(1.155 \%$ of the diocese population) and 3,153 demented nursing home residents $(0.556 \%$ of the diocese population).
According to the German Federal Institute for Population Research, in 2008 there were 38,505,603 Germans living in rural areas comparable to our research area ${ }^{34}$.

Given our results, one could extrapolate 444,706 nursing home residents in the rural areas of Germany with 214,168 among them with dementia. With regard to the increasing aging population, one could expect an even greater number of nursing home residents and demented people in the future. These large numbers mark how significant it is worldwide to prepare for the special treatment modalities for dementia and for the future costs.

\section{Conclusion}

We conclude that the prevalence of $48 \%$ for dementia in the nursing home population of the rural Passau area is comparable to those rates reported in nursing homes in rural areas of other countries. Given the likelihood of under-diagnosis due to various factors, including logistics and resources, this rate may well be an underestimation of dementia prevalence in this population.

Our study tends to show a higher prevalence of dementia in a rural nursing home population compared to studies of urban populations, which might be associated with a lower educational level and a higher life expectancy. Further studies are needed to directly compare the prevalence of dementia in rural and urban populations including their specific risk factors.

Considering the decreasing number of physicians and especially specialists in the rural area in the future and the growing number of elderly and thus persons with dementia who need medical support, the need of redistributing medical resources and a focus on 
research in the rural areas are increasingly important concerns.

Determining rates of dementia in the population is an initial step in estimating future costs and identifying the many issues in caring for this special patient population worldwide, especially regarding a higher life expectancy and thus an increasing number of afflicted individuals in the future. Psychogeriatric education is warranted to improve medical treatment of dementia in nursing home residents. As there is a lack of information on the rural population affected by dementia, further international research in this area will give important insights into the risk factors, the variables influencing the course of the disease, and the special care needs of this population.

\section{References}

1. Ziegler U, Doblhammer G. Prevalence and incidence of dementia in Germany-a study based on data from the public sick funds in 2002. Gesundheitswesen 2009; 71(5): 281-290.

2. Garrard J, Buchanan JL, Ratner ER, Makris L, Chan $\mathrm{HC}$, Skay C, et al. Differences between nursing home admissions and residents. J Gerontol 1993; 48(6): S301-S309.

3. Rovner BW, German PS, Broadhead J, Morriss RK, Brant LJ, Blaustein J, et al. The prevalence and management of dementia and other psychiatric disorders in nursing homes. Int Psychogeriatr 1990; 2(1): 13-24.

4. Jakob A, Busse A, Riedel-Heller SG, Pavlicek M, Angermeyer MC. Prevalence and incidence of dementia among nursing home residents and residents in homes for the aged in comparison to private homes. Z Gerontol Geriatr 2002; 35(5): 474-481.

5. Weyerer S, Schaufele M, Schrag A, Zimber A. Dementia disorders, behavior problems and the care of clients in geriatric day-care compared to residents in homes for the elderly: a cross-sectional study in eight communities in Baden. Psychiatr Prax 2004; 31(7): 339-345.

6. Keefover RW, Rankin ED, Keyl PM, Wells JC, Martin J, Shaw J. Dementing illnesses in rural populations: the need for research and challenges confronting investigators. J Rural Health 1996; 12(3): 178-187.
7. Shibayama H, Kasahara Y, Kobayashi H. Prevalence of dementia in a Japanese elderly population. Acta Psychiatr Scand 1986; 74(2): 144-151.

8. Nunes B, Silva RD, Cruz VT, Roriz JM, Pais J, Silva MC. Prevalence and pattern of cognitive impairment in rural and urban populations from Northern Portugal. BMC Neurol 2010; 10: 42.

9. Hutsteiner P, Maderer S, Stadlober-Degwerth M, Fronhofer W, Wurster H, Hajak G, et al. Genetische Alzheimerstudie eines ambulanten Patientenkollektives der Landkreise Regen, Freyung-Grafenau und Passau. Nervenheilkunde 2008; 27 (Suppl 1): 8-9.

10. Klunemann HH, Fronhofer W, Wurster H, Fischer W, Ibach B, Klein HE. Alzheimer's second patient: Johann F. and his family. Ann Neurol 2002; 52(4): 520-523.

11. Klunemann HH, Kloiber S, Wurster HW, Klein HE. Familial plaque-only Alzheimer's disease in the Rottal-Inn and Passau counties. Psychiatr Prax 2004; 31 Suppl 1: S61S63.

12. OECD. OECD Regions at a Glance. Paris: OECD Publications; 2005.

13. Annuario Pontificio 2008. 2008.

14. Engle VF, Graney MJ. Stability and improvement of health after nursing home admission. J Gerontol 1993; 48(1): S17-S23.

15. Tariot PN, Podgorski CA, Blazina L, Leibovici A. Mental disorders in the nursing home: another perspective. Am J Psychiatry 1993; 150(7): 1063-1069.

16. Canadian Study of Health and Aging Working Group. Canadian Study of Health and Aging: Study methods and prevalence of dementia. CMAJ 1994; (150): 899-913.

17. Class CA, Unverzagt FW, Gao S, Hall KS, Baiyewa $\mathrm{O}$, Hendrie HC. Psychiatric disorders in African American nursing home residents. Am J Psychiatry 1996; 153(5): 677-681.

18. Magaziner J, German P, Zimmerman SI, Hebel JR, Burton L, Gruber-Baldini AL, et al. The prevalence of dementia in a statewide sample of new nursing home admissions aged 65 and older: diagnosis by expert panel. Epidemiology of Dementia in Nursing Homes Research Group. Gerontologist 2000; 40(6): 663-672.

19. Alvarado-Esquivel C, Hernandez-Alvarado AB, Tapia-Rodriguez RO, Guerrero-Iturbe A, Rodriguez-Corral K, Martinez SE. Prevalence of dementia and Alzheimer's disease in elders of nursing homes and a senior center of Durango City, Mexico. BMC Psychiatry 2004; 4:3.

20. Brune-Cohrs U, Juckel G, Schroder SG. The quality of the diagnostic assessment of dementia in nursing homes. Z Arztl Fortbild Qualitatssich 2007; 101(9): 611-615. 
21. Bavarian Medical Society (Bayerische Landesärztekammer). 2010. Personal Communication

22. Ott A, Breteler MM, van Harskamp F, Claus JJ, van der Cammen TJ, Grobbee DE, et al. Prevalence of Alzheimer's disease and vascular dementia: association with education. The Rotterdam study. BMJ 1995; 310(6985): 970-973.

23. Bischoff R, Simm M, Zell RA. Der Kampf gegen das Vergessen. Demenzforschung im Fokus 2004.

24. Ikonomovic MD, Klunk WE, Abrahamson EE, Mathis CA, Price JC, Tsopelas ND, et al. Post-mortem correlates of in vivo PiB-PET amyloid imaging in a typical case of Alzheimer's disease. Brain 2008; 131(Pt 6): 1630-1645.

25. Klunk WE, Engler H, Nordberg A, Wang Y, Blomqvist G, Holt DP, et al. Imaging brain amyloid in Alzheimer's disease with Pittsburgh Compound-B. Ann Neurol 2004; 55(3): 306-319.

26. Bickel H. Epidemiologie der Demenzen. In: Förstl H, Bickel H, Kurz A, editors. Alzheimer Demenz. Grundlagen, Klinik und Therapie.Berlin, Heidelberg, New York: Spinger Verlag; 1999. p. 9-32

27. Paradise M, Cooper C, Livingston G. Systematic review of the effect of education on survival in Alzheimer's disease. Int Psychogeriatr 2009; 21(1): 25-32.

28. Prencipe M, Casini AR, Ferretti C, Lattanzio MT, Fiorelli M, Culasso F. Prevalence of dementia in an elderly rural population: effects of age, sex, and education. J Neurol Neurosurg Psychiatry 1996; 60(6): 628-633.
29. Shucksmith M, Cameron S, Merridew T, Pichler F. Urban-Rural Differences in Quality of Life across the European Union. Regional Studies 2012; 43(10): 1275-1289.

30. Fratiglioni L, Grut M, Forsell Y, Viitanen M, Grafstrom M, Holmen K, et al. Prevalence of Alzheimer's disease and other dementias in an elderly urban population: relationship with age, sex, and education. Neurology 1991; 41(12): 1886-1892.

31. Kyte L, Wells C. Variations in life expectancy between rural and urban areas of England, 2001-07. Health Stat Q 2010; (46): 25-50.

32. Shucksmith M, Roberts D, Scott D, Chapman P, Conway E. Disadvantage in rural areas. Rural Research Report 29. London; 1996.

33. Kim SY. The ethics of informed consent in Alzheimer disease research. Nat Rev Neurol 2011; 7(7): 410-414.

34. German Federal Institute of Population Research. 2010. Personal Communication.

Corresponding author:

Petra Hutsteiner

University of Regensburg, Department of Psychiatry

Universitätsstraße 84

93053 Regensburg

Germany

Phone: 0049-(0)941-9411221

Fax: 0049-(0)941-9411235

E-mail: petra.hutsteiner@web.de 